\title{
Development of the Lurian Approach: A Cultural Neurolinguistic Perspective
}

\author{
Bella Kotik-Friedgut ${ }^{1}$
}

\begin{abstract}
Published online: 31 May 2006
This article presents a discussion of the principle of extracortical organization of higher mental functions and its significance for the development of contemporary neuropsychology. The role of external factors (stimulus-mediator, symbol) in establishing functional connections between various brain systems is, in principle, universal. However, inasmuch as differing mediators and means, or significantly different details within them (direction of writing, orientation by maps or by the behavior of sea birds, etc.) may and in fact do develop in different cultures, neuropsychological analysis must take into account cross-cultural differences. Diagnostic tools must also be adapted to differing cultural contexts. The efficacy of this principle for the analysis of bilingual aphasia and of mental organization of speech, including the effect of acquisition of literacy in native language, is demonstrated. The importance of this principle for the development of new directions in applied neuropsychology is also discussed.
\end{abstract}

KEY WORDS: bilingual aphasia; cross-cultural neuropsychology; extracortical organization; higher mental functions; Lurian theory.

The role of Alexander Romanovich Luria in the foundation and development of contemporary neuropsychology is well known. The emphasis in this article is that analysis of impairment of psychological functions as a result of brain damage was for him not a primary aim, but only the main method of research involving the interaction of neurobiological and cultural systems. Jerome Bruner, who for many years corresponded frequently with Luria and also had many opportunities for personal discussions with him, admits that Luria's main concern was "... about the interdependence of the individual mind and the culture that enabled mind to grow in a manner to recognize and cope with complexities of the world, physical and social alike" (Bruner, 2005: xi-xii).

Our position in this discussion regarding the interaction of these factors is important for the development of an integrated psychological theory as well as ever-growing fields of applied neuropsychology. Some basic cognitive abilities and their corresponding brain mechanisms are universal and inherent for all humans, independent of lan-

\footnotetext{
${ }^{1}$ To whom correspondence should be addressed at, 13 Ishai St., Jerusalem, 93544, Israel; e-mail: bella.kotik@gmail.com.
}

guage and environmental conditions. At the same time, the process of internalization in the development of higher mental functions takes place under the influence of a specific cultural context, thus shaping and moderating the process of development and the functioning of these basic cognitive abilities. Neuropsychological investigations of cognitive processes, both in normal subjects and in patients with focal brain lesions, were performed with people who were educated in Europe, North America, and the former Soviet Union. These studies demonstrated a Eurocentric worldview that assumed that all people would manifest the same behaviors to the same stimulus in the brain (Fletcher-Jansen et al., 2000).

Neuropsychologists today, however, work with people in countries with differing cultures that are influenced by immigrants of different origins, with people with low levels of literacy, and with children in developing countries (Ardila, 2002; Ardila et al., 1989, 2000; Rosselli, 1993), where the educational system is still in the early stages of being established or access to education is limited. In this context, it has become apparent that the influence of culture has to be taken into account in the analysis of the development and of disturbances in mental 
processes. Culture is a broad and overarching concept, a complex entity that can have ethnic, geographic, generational, linguistic, and social determinants.

The need to take cultural factors into consideration is reflected in the field of neuropsychology in the last decade with the appearance of new topics with corresponding new terminology such as cross-cultural neuropsychology (Ardila, 1995; Fletcher-Jensen et al., 2000) and cultural neuropsychology (Kennepohl, 1999). Alfredo Ardila, a pupil of Luria, is largely credited with introducing the term "cross-cultural neuropsychology," formulating the most important directions for its development (Ardila, 1995), and he continues to contribute to the development of this field (Uzzell et al., 2006). It is now well accepted that neuropsychologists need to consider which concepts are universal and which are patient specific (FletcherJensen et al., 2000). Training programs in this field must be reconsidered (van Gorp et al., 2000).

It is well established that culture has a considerable influence on the development of the brain and its functions. The actual mechanisms, scope, and consequences for neuropsychological diagnostics, however, still require clarification. Understanding the relevant processes involved is particularly significant for psychoeducational practice for both normal and remedial teaching and learning. In the context of cultural psychology, biological factors are traditionally considered to be restrictive, i.e., it is accepted that there are some biological (genetic, neuropsychological) limitations on the influence of the sociocultural environment. There is even a type of fear of "biological reductionism" among developmental psychologists, especially among those involved in pedagogy and education. ${ }^{2}$ An example of such concerns arises in a context of behaviorally based recommendations. Thus, in one of the relatively new educational films on learning (produced in the United States), used to demonstrate the influence of experience in early childhood on brain development, data on increased brain weight of a mouse as a result of systematic stroking are provided, and based on this result in mice, frequent massaging of babies is recommended for fostering their brain development and cognitive functions. It is likely that massage of babies may have some benefit, but such a simplistic approach is not enough for "brain-based education."

Today, reviews of recent brain research are usual in the professional literature for teachers and parents. A recent book on sociopedagogy, From Neurons to Neighborhoods: The Science of Early Childhood Development,

\footnotetext{
${ }^{2}$ In personal communication with colleagues responsible for education of school psychologists in Russia the author tried to persuade them to include a neuropsychological course in the curriculum of school psychologists. They resisted, arguing against this kind of reductionism.
}

which is a report of a joint committee of the two US National Academies (of Sciences and Engineering), in collaboration with the Institute of Medicine and National Research Council, acknowledges that the "explosion of research in neurobiological, behavioral and social sciences has led to major advances in understanding conditions which influence whether children get off to a promising or a problematic start of life" (Shonkoff and Phillips, 2000: 1). Yet, publications on education concerning the problem of "brain and learning," often refer to culture or relate to the importance of understanding how the brain works, in a superficial manner (Cram and Germinario, 2000).

In this context, it is reasonable to suggest that for the field of applied neuropsychology, especially in education, it is particularly compelling to develop an adequate approach to the analysis of the interrelation of psychological and brain mechanisms. It is important to understand how the environment, and activity within a specific environment, influences the systemic-dynamic organization of higher psychological functions. For a psychologist or a teacher who is responsible for the development and accomplishment of rehabilitation or remedial programs, such understanding opens the way for a more effective use of existing techniques together with the creative use and invention of specific new methods, and techniques of learning and teaching.

\section{THE ROLE OF CULTURE IN ORGANIZATION OF HIGHER PSYCHOLOGICAL FUNCTIONS}

The method of personal address to colleagues was adopted from A. R. Luria, who used to send letters to colleagues in different countries asking them the same question. I sent out the same letters to colleagues and students in different countries with the question: "How do you understand and use (both in research and practice) the concept of extracortical organization of brain functions"?

The results of a survey reveal that apart from the circle of students of Luria, who are now spread widely over different countries, there is no clear comprehension of the meaning and significance of this concept in modern neuropsychology. Some respondents asked, "Do you mean subcortical?" and others asked for an explanation of the term.

In this context and on the occasion of the centennial celebration of Alexander Romanovich Luria, in 2002, it is appropriate to remember some of his basic ideas which are important for contemporary neuropsychology, in particular the concept of the "extracortical organization of higher mental functions." 
The systemic-dynamic approach in analysis of brain organization of higher mental functions developed by Luria $(1966,1973)$ is a logical extension and development of the ideas of L. S. Vygotsky regarding the interaction of nature and nurture and natural and cultural factors in the development of the human mind (Vygotsky, 1978).

Here it is appropriate to point out that for A. R. Luria and L. S. Vygotsky, the main object of their expeditions to Uzbekistan in 1930 and 1931 (the idea and planning was mutual, but only Luria actually traveled with a group of colleagues) was to investigate the influence of culture, and in particular, of its most important institution, education, on the development of higher mental functions (Luria, 1931, 1933, 1976). At that time, they succeeded in comparing cognitive processes in illiterate and literate people of the same culture. Illiterate men and women were involved in primitive individual farming while literate people of the same culture received some formal education, and their work in some industrial or agricultural enterprise or organization involved planning and coordination of activity with other workers. The results of experiments on classification of geometrical forms revealed that illiterate people from small villages gave names to geometrical forms based on their resemblance to real objects (plate, mirror, etc.), while literate individuals named the forms (circle, triangle, etc.). In classification of real objects, illiterate farmers appeared constrained by their personal experience, and more education in the literate group was associated with an increasingly easier shift to classification based on generalizations according to conceptual criteria. Similar results were obtained with logic tasks: illiterate people were unable to solve problems that were beyond their personal experience: "We always speak about things we see. We never speak about the things we did not see" (Luria, 1979). In other words, traditional thinking appeared to be bound to concrete situations of a real life. Luria attributed the ability to use abstract reasoning and formal categories to schooling.

The famous fatal telegram sent to Vygotsky by Luria from this travel to Middle Asia, that, "Uzbeks do not have illusions," contained not only a slightly humorous (rather typical of the Lurian sense of humor) hint, but also an important observation, which is now confirmed in several studies. Thus people who grew up in non-urban environments are much less prone to visual illusions of the Muller-Lyer type than people who are living in typical Western environments. Spatial abilities differ among cultures and depend on specific ecological demands (for a comprehensive review see Ardila, 1993).

Luria's developed an interest in cross-cultural aspects of mental development at the very beginning of his scientific work and never lost it when the development of neuropsychology became the focus of his interests.

He proposed that higher mental functions are “... social in origin and complex and hierarchical in their structure and ... based on a complex system of methods and means ..." (Luria, 1973: 30). An intrinsic factor in systemic organization of higher mental functions is the engagement of external artifacts (objects, symbols, signs), which have an independent history of development within culture. Luria wrote in his handbook of neuropsychology,

\footnotetext{
... higher forms of conscious activity are always based on certain external mechanisms (good examples are the knot which we tie in our handkerchief so as to remember something essential, .., or a multiplication table which we use for arithmetical operations)- it becomes perfectly clear that these external aids or historically formed devices are essential elements in the establishment of functional connections between individual parts of the brain, and that by their aid, areas of the brain which previously were independent become components of a single functional system. This can be expressed more vividly by saying that historically formed measures for the organization of human behavior tie new knots in the activity of man's brain and it is the presence of these functional knots, or, as some people call them, 'new functional organs' (Leontiev, 1959), that is one of most important features distinguishing the functional organization of the human brain from an animal's brain. It is this principle of construction of functional systems of the human brain that Vygotsky (1960) called the principle of 'extracortical organization of complex mental functions,' implying by this somewhat unusual term that all types of human conscious activity are always formed with support of external auxiliary tools or aids. (Luria, 1973: 31)
}

Among other uses, Luria applied this proposition to development of rehabilitation of higher psychological functions. During World War II, he headed a group working in a hospital for soldiers recuperating from head injuries. For motor rehabilitation, instead of direct training of hand movements they included movement as a means of reaching (grasping, switching, etc.) for different objects (Luria, 1964). Thus, attention shifted from movement itself to purposeful activity, and the relationship of such activity to different (external) objects evoked a variety of movements.

According to the concept of "extracortical organization of complex mental functions," the role of external factors in establishing functional connections between various brain systems is, in principle, universal. However, different mediators and means, or significantly different details within them (e.g., the direction of writing and degree of letter-sound correspondence, orientation by maps or by the behavior of sea-birds, etc.) may develop, and in fact are developed in different cultures. Therefore, 
the analysis of higher mental functions must necessarily take into account these cross-cultural differences. In other words, brain-behavioral relationships are interwoven and are dependent on environmental influences (Fletcher-Jansen et al., 2000: vii).

\section{CROSS-CULTURAL AND NEUROPSYCHOLOGICAL ANALYSIS OF HIGHER MENTAL FUNCTIONS IN THE SCIENTIFIC WORK OF A. R. LURIA AND HIS STUDENTS}

At one of his traditional clinical investigations, A. R. Luria was analyzing the case of a patient, who during the acute stage immediately following a stroke, had many more problems recalling familiar verses in Russian, her native language, than in English, which was the language in which she was teaching. Soon afterward, we encountered a similar case in which once more the vernacular was more disturbed than the foreign language, leading to the formulation of a systemic-dynamic interpretation of bilingual aphasia (Kotik, 1979, 1984, 1992, 1996, 2001). For the development of this model, the concept of "extracortical organization of mental functions" is especially important. Essentially, it is the central idea for finding an explanation for one of the most distinct and interesting features of bilingual aphasia cases - the vast variety of patterns of disorders and/or of rehabilitation dynamics in bilingual aphasics (Albert and Obler, 1978; Fabbro, 1999; Paradis, 1977, 1983).

Among the articles I received from Luria on this topic was also one of his own papers, which described the case of a French journalist who had suffered from alexia in all languages at his command (French, Russian, German, and Polish). Agraphia was most severe in French and least in Russian. Luria's interpretation of this differential agraphia in different languages of a polyglot patient was based on the cross-linguistic analysis of the sound-symbol correspondence, which in Russian is much closer than in French, where many symbols can combine to make one sound or are simply not pronounced. In addition, the patient only used the Cyrillic alphabet in Russian, while all three other languages use the Latin script (Luria, 1956).

The central issue in bilingual aphasic research has generally been the following: Are the brain mechanisms for speech in bilingual individuals the same or different for the two languages? The phenomenon of language dissociation, (i.e., different disorders and/or the rehabilitation of different languages) found in bilinguals with aphasia usually has been considered as evidence that there are different brain mechanisms or different localization for each language. Therefore, for a long time, descriptions of unique cases dominated the literature on aphasia in bilingual individuals (for reviews, see Albert and Obler, 1978; Paradis, 1983). Later, with the development of aphasiology in countries where bilingualism is widespread, it became clear that parallel or similar disorders in different languages of bilingual patients with aphasia are most typical, while language dissociation is rather exceptional. Accordingly, parallel disorders and/or the rehabilitation are all interpreted as proof of common or shared mechanisms of different languages in the brain of a bilingual. At present, with the development of computerized imaging of the working brain, it has become possible to organize research on healthy subjects; yet, the same problem of the same-different localization of different languages appears in discussions of research results (Fabbro, 1999; Kim et al., 1997; Paulesu et al., 2000).

Attempts at generalization and systematization of bilingual aphasia started from monofactorial hypotheses, and only later were various lists of factors considered (for review see Kotik-Friedgut, 2001). The systemic-dynamic approach in the analysis of the brain organization of higher mental functions rejects any attempt to interpret aphasic symptoms in bilinguals, or any neuropsychological problem, as stemming from any single factor, and offers an alternative explanation. This approach requires that neuropsychological analysis include a demonstration of a system of interrelated factors associated with the development and disturbance of a function under consideration. This is particularly true in view of the complexities of bilingualism. According to Vygotsky's (1934) analysis, the course of psychological development of the first language in early childhood tends to be universal, while bilingualism in each individual case is a product of a combination of different factors (social, cognitive, linguistic, and biological).

The development of bilingualism and new language learning are usually the focus of attention of sociolinguists, psycholinguists, and researchers working in technologies of language teaching in multilingual countries. They deal with the speech of healthy people and the speech behavior of groups, while neuropsychologists have dealt with cases of aphasia or have experimentally manipulated stimuli for healthy subjects in a laboratory situation. From the psychological aspect, different factors are involved in foreign language learning and second language acquisition. The main difference is in sociocultural contexts. Foreign language is often learned outside of the culture and milieu of native speakers of the target language, while the motive for second language learning and acquisition is to acculturate and to live within the culture of the target language. 
In attempts to develop theories of second language learning, different data from neuroscience are referred to (Schumann, 1998). However, in neuropsychological analysis the nuances of the process of language learning or acquisition are not taken in full as a system of interrelated factors relevant to brain organization of speech and language.

A system of factors of different types and natures related to language acquisition and use, on the one hand, and neurological factors, on the other hand, must be taken into consideration. The variety of syndromes in bilingual aphasia - as well as the variety of the results of laboratory experiments — can be predicted, based on the approach developed by Luria $(1956,1973)$. In terms of this approach, the problem of shared versus differential localization of languages in the bilingual brain cannot have a definite answer without specifying the subject's characteristics (e.g., age and manner of second language acquisition, language proficiency, etc.), or the experimental task demands (e.g., listening to a story, repeating words, orally generating synonyms of words presented orally, etc.).

In neuropsychological analysis of bilingual aphasia, all the variables and dynamics of the process of the development of bilingualism (language anamnesis) have to be taken into consideration, along with details of the neurological syndrome. Special attention is paid to the circumstances and the manner of second language acquisition. According to the principles of dynamic and extracortical organization of brain functions, the characteristics of the ways of development of a certain function (e.g., speech, reading, and writing in a second language) are intrinsic for shaping the pattern of brain zones involved in the regulation of the specific functions. Stemming from such an approach, the variety of factors related to second language acquisition and use become critically important for neuropsychological analysis.

Thus, age or the level of motivation, the tools, and the information channels used in language learning each has its importance in terms of shaping the functional system of speech functions in the second language. For example, age at the start of second language learning is associated with maturity of brain functions, and a certain level of cognitive and speech development in the first language. The formal learning of a foreign language with an emphasis on reading and writing predominantly involves visual perception and visual memory as basic channels of input. In contrast, during the development of the mother tongue in early childhood, the verbal-visual factor becomes operative only with the start of schooling. In children blind from birth, in whom the visual channel is unavailable, the tactile perception becomes active in verbal processes only with the acquisition of literacy.
Second language acquisition in immigrants living in the culture of the target language entails all possible channels of input (e.g., street names and shopping, texts of different registers and styles, and communication with native speakers on different occasions). To some degree, the manner of language learning determines which components will be involved in the development of a new functional system. For example, in research involving Russian and Estonian (Kotik, 1979), interhemispheric asymmetry (measured by the right ear effect in verbal dichotic listening tests) for word processing in the first and second language was observed, related to the way the second language was acquired and for which purposes it had been used. In Russian-Estonian bilinguals, the lateral effects in both languages were similar, while in Estonian-Russian bilinguals the right ear effect was greater for Russian words. Interestingly, the conditions for the second language acquisition in the two groups were different. The Russians acquired and used Estonian as a second language, communicating in a natural language environment. This means that all input modalities were exploited and the psychological structure of the process of language acquisition of both first and second languages was similar. On the other hand, the Estonians learned Russian mainly for academic and instrumental reasons in a predominantly formal way (e.g., reading handbooks), using it mostly for professional purposes. Correspondingly, the visual input modality was primary and translations were used to improve proficiency.

However, in this case, like many others, the method of learning is intrinsically related to another important factor: age. The problem of age differences in language learning has been discussed extensively among experts in language learning ever since the Hypothesis of the Critical Period was suggested. The hypothesis claims that humans are capable of proficient language learning (both mother tongue and second language) only before the early teens, and that afterward the brain mechanisms are "frozen," with proficiency never reaching a level of perfection (in particular, ridding oneself of a foreign accent was considered impossible) (Lenneberg, 1967). A variety of explanations were suggested for the apparent decline in the abilities of new language learning in adults: physical such a loss of "plasticity" and established "lateralisation" of the brain; social factors such as different relationships; life situations and such cognitive explanations as different degrees of interference with natural language learning; and the adult's abstract mode of thinking (Cook, 1991).

In his lecture on development of memory, L. S. Vygotsky explained the differences in new language learning between children and adults, and concluded that they use different learning strategies because of the 
developmental differences in the interrelation between various cognitive functions. "In early childhood, memory is the dominant function. It defines the child's thinking. Correspondingly, transition to abstract thinking leads to a different type of remembering." (Vygotsky, 1932/1987: $310)$. In agreement with this principle, the corresponding pattern of relevant brain structures also changes with age. If at an early age damage to a specific cortical area causes a relatively elementary basis of mental activity, it unavoidably causes as a secondary "systemic" effect, or an underdevelopment of higher structures built on these elementary functions. In mature adults, the opposite is true; damage to the "higher zones" leads to decomposition of elementary functions intimately dependent on higher forms of activity (Luria, 1973).

Preschool children can learn a second or foreign language, but the ways of language learning cannot involve the study of explicit grammar rules or written forms of language. Thus, primarily auditory perception of speech in the context of communication and games will be used. In adult language learning, visual input often plays the major role. Older pupils and adults can use not only books, but can also work with learning aids, such as parallel reading and listening to a recorded text, or multimedia computer programs. Correspondingly, according to the principle of extracortical organization of higher mental functions, a different involvement of cortical auditory and visual areas can be predicted. Therefore, it is reasonable to expect that in early bilingualism resulting from more or less parallel acquisition of two languages, the brain organization for both will be quite similar. We can expect differences in aphasic syndromes in early bilingual individuals only in the case of significant linguistic differences between the two languages, mainly with respect to literacy (if the two languages of a bilingual differ in sound-symbol correspondence, the direction of reading and so forth), while the mechanisms of auditory speech perception will be similar.

Thus, in countries in which early bilingualism is a common phenomenon the most typical cases of aphasiological research are those in which both languages are impaired in similar ways (review in Albert and Obler, 1978). According to Chihladze (1986), in cases of Georgian-Russian bilingualism, the frequency of language dissociation in aphasic patients is not more than $2 \%$. The neuroimaging studies, which included early bilinguals, report overlapping areas of activation for native and second languages. The systems for languages learned later in life display a high degree of variability between individuals (Neville and Bavelier, 1998).

Even in the case where two languages are acquired simultaneously; however, different patterns of usage and/or literacy (learning to read and write) are possible, depending on the sociocultural context of education. Formal studies may be organized in one of the languages or in both, simultaneously in two languages, or successively, accounting for the observation that the most frequently reported dissociation is in reading and/or writing (Hinshelwood, 1983; Luria, 1956; Nair and Virmany, 1973).

If the languages are acquired successively rather than simultaneously, it is reasonable to expect differences in their neurological organization. First, at the time of acquisition of each language, the brain is at a different stage of maturation, resulting in differences in cognitive development, as we discussed previously. In new language learners, the involvement of established systems of the first language is unavoidable. There is a clear transfer of skills and correlation between levels of development in two languages in bilingual individuals (Cummins, 1991). Underdevelopment of a specific function in the native language may be reflected in a similar deficiency in the second language.

It seems relevant to recall that in 1928, Vygotsky emphasized that "The entire problem of bilingualism should be approached not statically, but dynamically" (Vygotsky, 1928/1983: 334). There is also a corresponding dynamic in brain mechanisms. An essential characteristic of the localization of higher mental processes is that it is never static or constant. It moves about during both child development and the subsequent stages of training. The development of any type of complex conscious activity is at first expanded in character and requires a number of essential aids for its performance; not until later does it gradually become condensed and converted into an automatic (motor) skill (Luria, 1973).

Second language acquisition is a continuous process that can develop at different levels of mastery of various speech functions. In other words, one person can be fluent in speech, but not practice reading; another can translate complex written texts perfectly but not be fluent orally. Even in adults, there are changes in the development of skills at different stages of training that correlate with functional changes in brain mechanisms. The research data regarding changes in the pattern of interhemispheric communication at different stages of mastering a new language indicate changes in the pattern of interhemispheric relations in the processing of stimuli during the acquisition of a second language according to the stages of development of bilinguality (Kotik, 1984).

These findings have been generally consistent with the results of other researchers who have worked on the development of the native language (Gordon, 1980; Silverberg et al., 1979). The study by Silverberg and his 
colleagues (1979) revealed that there is a shift in the lateral effects in the tachistoscopic perception of Hebrew words during acquisition of the reading process in native Hebrew speakers. This means that learning to read in one's first language may affect the functional lateral organization of the brain. A constellation of various potentially possible factors relevant to the process of bilingual development that can influence the brain organization of languages is presented in a recent paper (Kotik-Friedgut, 2001).

\section{BRAIN ORGANIZATION OF SPEECH AND EDUCATION}

Acquisition of literacy is usually associated with schooling, and its profound effect is reflected in all spheres of cognitive functioning. At pre-literacy stages of development auditory comprehension of speech is related to visual perception mainly as recognition of the source of the message human (face) or cultural artifact (telephone, radio, etc.). It is a tangible, and not a symbolic, relationship. As reading skills are acquired, phonological awareness, the sound-letter relationship develops into a symbolic relationship. This is a somewhat prolonged process. New functional connections emerge and develop intervening auditory (temporal) and visual (occipital) zones of the brain. During the learning of writing, sensory-motor (parietal) zones become involved and attached to the auditory-visual functional connections, thus contributing to the maturation and development of the temporalparietal-occipital zone so important for the simultaneous synthesis essential to higher cognitive functions (Luria, 1973).

It was observed that European children around the age of 12 typically perceive pictures with threedimensional perspective. African children and illiterate Bantu and European laborers responded to the same pictures as flat, not three-dimensional (Hudson, 1962). They cannot interpret three-dimensional figures presented on paper. This also generally holds true for illiterate people (Ardila et al., 1989). The fact of schooling per se independently of a specific culture-in India or in Europe-has a significant input, predominantly on the processes of simultaneous and successive synthesis, while in the tasks of picture remembering or in tasks of a Piagetian type, the rates of illiterate and schooled children were similar (Baral and Das, 2002).

Based on the observation that illiterate subjects score significantly lower in some neuropsychological tests, Ardila et al. (2000) developed a method for learning to read, called NEUROALFA, aimed at reinforcing these particular undeveloped abilities during the learning- to-read process. It has proved to be significantly more effective than traditional methods in teaching illiterate Mexican adults (Ostrosky et al., 1999). An important finding was that after learning to read, all subjects-both in experimental and control groups - improved their performance in neuropsychological tests, although the gain of the group that had studied by the Neuroalfa method was significantly higher in some subtests, especially in all recall tasks, verbal tasks, and even in tasks such as Orientation in Time, Digits Backward, Visual Detection, Copy of a Semi - complex figure, Similarities, Calculation Abilities, and Sequences. It is important to emphasize that in this study there were generally low and nonsignificant correlation between pretest scores on a neuropsychological test and reading ability scores. The correlations between posttest neuropsychological test scores and reading ability scores; however, were significant in several subtests. This observation supports the assumption that neuropsychological test scores indeed do not exactly predict learningto-read scores, but learning to read reinforces the abilities required to obtain a high performance in neuropsychological tests. This observation may be important in the cognitive testing domain and in the analysis of the relationship between education and cognitive test performance.

The principle of extracortical organization of higher mental functions serves as a plausible framework for analysis of literacy and schooling. At the preliterate stage, the analysis of speech starts from auditory input. The visuo-auditory link is limited to the identification of the source of the utterance, while in reading this link is mediated by visual symbols. Learning to read involves the establishment of associations between sounds and graphic symbols-letters, synthesizing rows of these symbols into meaningful words, synthesizing groups of words into sentences, which describe objects and events of reality. Learning to write requires the use of significant graphomotor and visuospatial abilities that are not crucial for reading and are not reinforced when just learning to read. Learning the written form of language (orthography) interacts with the function of oral language (Castro-Caldas et al., 1988).

Reading skills can influence the spatial organization of perception. A cross-cultural comparison of the direction of picture naming in Russian and Arab children in Israel (Badarni, 2002) revealed no cultural differences in preschool children. In the third grade, after children are immersed in study activities within their specific cultures (i.e., the Arab children learned to read and write in Arabic and Hebrew from right to left, while Russian pupils read and wrote in the left-right direction), differences in spatial organization of perception were revealed. All Arab children name pictures starting from the right, moving left, while all Russian children do this in the opposite direction. 
All of these processes develop new functional connections between the brain regions connections serving these specific activities. In other words, new brain functional systems are developing via an external graphic symbol. After these links are established, a person receives a powerful instrument for further development and education, opening new ways of problem solving in different domains.

\section{SUMMARY AND PROSPECTIVE}

Vygotsky's concept of extracortical organization of higher mental functions developed by Luria appears to be particularly useful for understanding the cultural impact on cognitive processes. Oral language demands only audio-verbal processing. Literacy, or reading skills, being a cultural extension of oral language, gives rise to new strategies in the organization and interpretation of information. This process is mediated by the elements available in the environment depending on the cultural-historical context. The brain zones providing an analysis of symbolic graphic stimuli-i.e., letters-become involved in the language functional system only as a result of studying. Learning to write involves an additional motor factor. Thus, the graphic signs of written language (external) are essential factors in extracortical involvement in the development of language brain mechanisms. Both reading and writing include a visuospatial element (e.g., pattern of letters, direction of writing and position of the text on a paper or on a computer screen, etc.). This notion explains the effects of literacy, which produce changes traced not only in verbal processes, but also in visuospatial perception, and virtually in all cognitive functioning. Only literate people can use maps, read street and other road signs, cook using published recipes, choose appropriate products in a supermarket by reading names and descriptions, and so forth. Literacy therefore opens different ways of survival and adaptation.

A Lurian systemic-dynamic approach to the problem of bilingualism proves to be productive for solving the puzzle of the variability of aphasic syndromes in bilinguals. This theory, which incorporates the principle of extracortical organization of higher mental function, demands a careful analysis of methods and aids in language learning, including, the manner of acquisition, prevalent modality of input in language learning and use, learning strategies, and use of technical aids. Awareness of how the organization of the study process affects language proficiency is important for the education of language teachers and consequently for a more effective outcome of learning a new (second, foreign) language. The results of research of brain mechanisms of bilingualism underlie the development of a system of psychological support in new language learning (Kotik, 2002).

Methods of rehabilitation of cognitive processes for patients with local brain damage were successfully developed with of Luria's model (Luria and Tsvetkova, 1992). Reviewing the cultural-historical approach as basis for neuropsychology of the twenty-first century Glozman (2002) considers the modern trend of development of neuropsychology as occurring within the framework of "higher mental functions (brain)-society," which includes all aspects of individual existence in culture and society related to brain functioning both normal and deficient, both rehabilitation and prevention, both developing and aging individuals.

Now, in Moscow, Luria's pupils lead several successful centers of remedial pedagogy (Glozman and Potanina, 2001; Mikadze and Korsakova, 1994; Pylayeva and Akhutina, 1997; Semenovich, 2002; Semenovitch et al., 1992). While a comprehensive review of the contemporary state of Lurian neuropsychology is beyond the scope of this article, it is worth mentioning that two representative volumes of papers presented at the first and second memorial Luria conferences were published in Russian (Homskaya and Akhutina, 1998, also Akhutina and Glozman, 2003) and an English version of selected articles based on presentations at Luria memorial conferences is published in a Festshrift celebrating the centennial of the birth of Luria (Akhutina et al., 2005).

In Canada, J. Das directs a combination of research and remedial practice with mentally retarded children: the PASS model (Planning, Attention, Simultaneous, Successive) is based on a Lurian approach (Das, 2002). As noted in the preceding text, Ardila's method NEUROALFA for teaching literacy to adults is based on exercises enhancing specific cognitive abilities. Thus, on the basis of the Lurian systemic-dynamic foundation and creatively applying the principle of extracortical organization of higher mental functions, pupils of Luria in different countries are discovering new fields for the practical application of his ideas.

\section{ACKNOWLEDGMENTS}

This work was supported by a stipend from the Israeli Ministry of Absorption. The author expresses deepest appreciation to friends and colleagues Alfredo Ardila, Dorothy Robbins and Yvette Huss, for valuable comments and to Ted Friedgut for correcting my English. 


\section{REFERENCES}

Akhutina, T. V., and Glozman, J. M. (Eds.) (2003). Alexander Luria and the Psychology of the XXI Century. Proceedings of the Second International Luria Memorial Conference. Smysl, Moscow (in Russian).

Akhutina, T. V., Glozman, J. M., Moscovich, L., and Robbins, D. (Eds.) (2005). A.R Luria and Contemporary Psychology: Festschrift Celebrating the Centennial of the Birth of Luria. Nova Science Publishers, New York.

Albert, M., and Obler, L. (1978). The Bilingual Brain. Academic Press, New York.

Ardila, A. (1993). Historical evolution of spatial abilities. Behav. Neurol. 6: $83-88$.

Ardila, A. (1995). Directions of research in cross-cultural neuropsychology. J. Clin. Exp. Neuropsychol. 17:143-150.

Ardila, A. (2002). The impact of culture on neuropsychological test performance. In: Uzzell, B., Pontón, B., and Ardila, A. (Eds.), International Handbook of Cross-Cultural Neuropsychology. Erlbaum, Mahwah, NJ.

Ardila, A., Rosselli, M., and Rosas, P. (1989). Neuropsychological assessment in illiterates: Visuospatial and memory abilities. Brain Cogn. 11:147-166.

Ardila, A., Ostrosky, F., and Mendoza, V. (2000). Learning to read is much more than learning to read: A neuropsychologically-based learning to read method. J. Int. Neuropsychol. Soc. 6:789-801.

Badarni, A. (2002). Neuropsychological diagnostic of memory development in young schoolchildren-cross-cultural research. Dissertation abstract, MSU, Moscow.

Baral, B. D., and Das, J. P. (2002). Intelligence: What is indigenous to India and what is shared. In: Sternberg, R. J., and Grigorenko, E. (Eds.), International Handbook on Intelligence. Cambridge University Press, New York, pp. 270-301.

Beveridge, W. M. (1940). Some racial differences in perception. Br. J. Psychol. 30:57-64.

Bruner, J. (2005). Preface. In: Akhutina, T. V., Glozman, J. M., Moscovich, L., and Robbins, D. (eds.), A.R Luria and Contemporary Psychology: Festschrift Celebrating the Centennial of the Birth of Luria, Nova Science Publishers, New York, pp. xi-xiii.

Castro-Caldas, A., Peterson, K. M., Reis, A., Stone-Elander, S., and Ingvar, M. (1988). The illiterate brain. Learning to read and write during childhood influences the functional organization of the adult brain. Brain 121:1053-1064.

Chichladze, M. G. (1986). Verbal semantic relations in bilingual aphasic patients, Dissertation abstract. Tbilisi (in Russian).

Cook, V. (1991). Second Language Learning and Teaching, Edward Arnold, London.

Cram, H., and Germinario, V. (2000). Leading and Learning in Schools Brain-Based Practices, Scarecrow Press, Lanham, MD.

Cummins, J. (1991). Interdependence of first- and second-language proficiency in bilingual children. In: Bialystok, E. (Ed.), Language Processing in Bilingual Children. Cambridge University Press, New York.

Das, J. P. (2002). A better look at intelligence. Curr. Direct. Psychol. Sci. 11: 28-33.

Fabbro, F. (1999). The Neurolinguistics of Bilingualism: An Introduction, Psychology Press, Hove, UK.

Fletcher-Jansen, E., Strickland, T., and Reinolds, C. (2000). Preface. In: Fletcher-Jansen, E., Strickland, T., and Reinolds, C. (Eds.), Handbook of Cross-Cultural Neuropsychology. Kluwer Academic, New York, pp. $3-7$.

Glozman, J. (2002). Cultural historiacal approach as the basis of neuropsychology in the XXI century. Vopr. Psychologii 4:62-68 (in Russian).

Glozman, J., and Potanina, A. (2001). Communication disorders and a disadaptation to school. Vestnik Moskovskogo Universiteta. Seriya 14, Psikhologia 3:35-46 (in Russian).

Gordon, H. (1980). Cerebral organization in bilinguals. Brain Lang. 9:225-268.
Hinshelwood, J. (1983). Four cases of word blindness. In: Paradis, M. (Ed.), Readings on Aphasia in Bilinguals and Polyglots. Didier, Quebec, Canada, pp. 64-67.

Homskaya, E. D., and Akhutina, T. V., (Eds.), (1998). Proceedings of the First International Luria Memorial Conference, Psychological Association of Russia, Moscow (in Russian).

Hudson, W. (1962). Cultural problems in pictorial perception. South African Journal of Sciences 58:189-195.

Kennepohl, S. (1999). Toward cultural neuropsychology: An alternative view and preliminary model. Brain Cogn. 41:345-362.

Kim, K. H., Relkin, N. R., Lee, K. M., and Hirsch, J. (1997). Distinct cortical areas associated with native and second languages. Nature 388: $171-174$

Kotik, B. (1979). Investigation of speech lateralization in polyglots. Voprosy Psychologii, 1:74-78 (in Russian).

Kotik, B. (1984). On the role of the right cerebral hemisphere in speech of bilinguals. In: Ardila, A., and Ostrosky, F. (Eds.), The Right Hemisphere: Neurology and Neuropsychology. Gordon and Breach, New York, pp. 227-240.

Kotik, B. (1992). Human Interhemispheric Cooperation, Rostov University Press, Rostov-on-Don (in Russian).

Kotik, B. (1996). A multidimensional approach to aphasia in bilinguals. J. Israel Speech Hear. Lang. Assoc. 19:90-100.

Kotik-Friedgut, B. (2001). A systemic-dynamic Lurian approach to aphasia in bilinguals. Commun. Disord. Q. 22:138-160.

Kotik-Friedgut, B. (2002). Teachers and students sharing a challenge of new language learning-psychological support in the process. The Fourth International Conference on Teacher Education. Conference Abstracts 2. Achva, Tel Aviv, p. 312.

Krashen, S. (1982). Principles and Practice in Second Language Acquisition, Pergamon Press, Oxford.

Lenneberg, E. H. (1967). Biological Foundation of Language, John Wiley, New York.

Leontiev, A. N. (1959). Problems of Mental Development, Academy of Pedagogical Science, Moscow (in Russian).

Luria, A. R. (1931). Psychological expedition to central Asia. Science 74: 383-384.

Luria, A. R. (1933). The second psychological expedition to central Asia. Science 78:191-192.

Luria, A. R. (1956). On the problem of reading and writing disturbance in polyglots. Fiziologicheskyj zhurnal 2:173-177 (in Russian).

Luria, A. R. (1964). Restoration of Brain Functions After War Trauma, Pergamon Press, New York.

Luria, A. R. (1966). Higher Cortical Functions in Man. Basic Books, New York.

Luria, A. R. (1973). The Working Brain, Penguin Books, London.

Luria, A. R. (1976). Cognitive Development: Its Cultural and Social Foundations, Harvard University Press, Cambridge, MA.

Luria, A. R. (1979). The Making of Mind, Harvard University Press, Cambridge, MA.

Luria, A. R., and Tsvetkova, L. S. (1992). The Neuropsychological Analysis of Problem Solving (Classic Soviet Psychology Series), Paul Deutsch Press, Orlando.

Mikadze, Yu. V., and Korsakova, N. K. (1994). Neuropsychological Diagnostics and Correction of Junior Schoolchildren, Intelteks, Moscow (in Russian).

Nair, K., and Virmani, V. (1973/1983). Speech and language disturbances in hemiplegics (summary). In: Paradis, M. (Ed.), Readings on Aphasia in Bilinguals and Polyglots. Didier, Quebec, Canada, pp. 791-792.

Neville, H., and Bavelier, D. (1998). Neural organization and plasticity of language. Curr. Opin. Neurobiol. 18:254-258.

Ostrosky, F., Ardila, A., Rosselli, M., Lopez-Arango, G., and Uriel - Mendoza, V. (1998). Neuropsychological test performance in illiterates, Arch. Clin. Neuropsychol. 13: 645-660.

Paradis, M. (1977). Bilingualism and aphasia. Stud. Neuroling 3:65121.

Paradis, M. (Ed.) (1983). Readings on Aphasia in Bilinguals and Polyglots, Didier, Quebec, Canada. 
Paulesu, E., McCrory, E., Fazio, F., Menoncello, L., Brunswick, N., and Capp, F. (2000). A Cultural Effect on Brain Function. Nat. Neurosci. 3:91-96.

Pylayeva, N., and Akhutina, T. (1997). School of Attention: Method of Attention Development and Correction in 5-7 Year Old Children, Intor, Moscow (In Russian).

Rosselli, M. (1993). Neuropsychology of illiteracy. Behav. Neurol. 6:107-112.

Schumann, J. (1998). The neurobiology of affect in language. Lang. Learn 48:(Suppl 1):

Semenovich, A. V. (2002). Neuropsychological Diagnostics and Remediation of Children, Academia, Moscow (In Russian).

Semenovitch, A., Umrikhin, S., and Tsyganok, A. (1992). Neuropsychological Analysis of Poor Learning Progress of Some of the Pupils of Ordinary Schools. Zhurnal-Vysshey-Nervnoy-Deyatel' nosti 42(4): 655-663 (in Russian).

Shonkoff, J., and Phillips, D. (2000). From Neurons to Neighborhoods: The Science of Early Childhood Development. National Academy of Science Press, Washington, DC.

Silverberg, R., Bentin, S., Gaziel, T., Obler, L. K., and Albert, M. L. (1979). Shift of visual field preference for English words in native Hebrew speakers. Brain Language 8: 184 190.

Uzzell, B., Pontón, M., and Ardila, A. (Eds.), (2006). International Handbook of Cross-cultural Neuropsychology. Lawrence Earlbaum Associates, Hillsdale, NJ.

Van Gorp, W. Myers, H., and Drake, E. (2000). Neuropsychological training: Ethnocultural considerations in the context of general competency training. In: Fletcher-Jansen, E., Strickland, T., and Reinolds, C. (Eds.), Handbook of Cross-Cultural Neuropsychology. Kluwer Academic, New York, pp. 19-27.

Vygotsky, L. S. (1934/1985). Thought and Language. The MIT Press, Cambridge, MA.

Vygotsky, L. S. (1960). Development of Higher Mental functions. Academia Pedagogical Sciences, Moscow (in Russian).

Vygotsky, L. S. (1978). Mind in Society, Harvard University Press, Cambridge, MA.

Vygotsky, L. S. (1932/1987). Lecture 2. Memory and its development in childhood. Collected Works. Vol. 1, Plenum Press, New York, pp. 301-310.

Vygotsky, L. S. (1928/1983). The problem of multilinguality in childhood. Collected Writings, Vol. 3. Pedagogica, Moscow (in Russian), pp. 327-329. 